\title{
TRADUÇÕES EM PROSA DA ODISSELA DE HOMERO: EXEMPLOS E PROBLEMAS
}

\author{
André Malta* \\ Universidade de São Paulo
}

\begin{abstract}
My aim is to discuss four Portuguese translations of Homer's Odyssey. Two were written in prose (by Dias Palmeira/ Alves Correia and by Jaime Bruna), in the 20th century, and two in free verse (by Frederico Lourenço and by Donaldo Schüler), in the 21st century. A quick review of these examples reveals that all of them want to recover Homer's narrative fluidity, without giving attention to its main formal aspects - which surely enhance the understanding of the contents. As to the latest versions, it is possible to claim that, despite the impressive differences between them, deployment of a free verse betrays the goal of only establishing a line by line correspondence between the original text and the translation, and in the end the principles of a prose translation seem again to guide these versions to Portuguese.

KEYWORDS: Homer; Odyssey; prose translation.
\end{abstract}

s traduções de Homero para as línguas modernas, desde as primeiras edições em grego da Ilíada e da Odisseia no final do século XV, representam um capítulo fascinante na história da literatura ocidental. Vista em conjunto, é uma produção rica e variada, que reflete não só o desenvolvimento das literaturas nacionais, com suas diferentes fases e tendências, mas também o modo como Homero foi sendo lido e interpretado — desde as visões recuadas (mais retóricas e a-históricas) até as mais recentes e próximas de nós (historicistas e especializadas).

$\overline{\star \text { andremal@uol.com.br }}$ 
Grosso modo, é possível dividir as traduções em três tipos — e penso aqui apenas naquelas que tiveram impacto maior nos ambientes em que foram publicadas (deixando de lado as com propósito meramente escolar):

1) as poéticas e não acadêmicas, até o final do século XVIII/ início do XIX, que deveriam tratar Homero sobretudo como grande poeta, preservando seu "espírito";

2) as especializadas, a partir do século XIX, que queriam dar a Homero um tratamento mais histórico, o que possibilitava um esvaziamento do elemento literário ou a recriação formal em correspondência direta com o original; e

3 ) as derivadas do movimento modernista, a partir do século $X X$, que abriram espaço para a exploração de novos recursos (e a revalorização do verso), além de admitirem às vezes um rebaixamento do tom épico, quando não adotavam a mais pura coloquialidade.

Em língua inglesa, cujo repertório de traduções homéricas, como se sabe, é espantoso (veja-se o livro de George Steiner, Homer in English, de 1996), poderíamos dizer que Alexander Pope é o maior representante do primeiro tipo; as versões "bíblicas" de Lang, Leaf \& Myres (Ilíada) e Butcher \& Lang (Odisseia), ou as recriações "hexamétricas" parciais do conhecido Matthew Arnold, do segundo; e os trabalhos de E. Rieu, ou ainda de Robert Fitzgerald e Robert Fagles, do terceiro. No Brasil, seria possível pensar, mantendo a correspondência, nos nomes de Odorico Mendes (tipo 1), Carlos Alberto Nunes (tipo 2) e Haroldo de Campos (tipo 3).

Mas onde situar, nesse quadro amplo e nada estático, o papel das traduções especificamente feitas em prosa? É certo que elas só começaram a ganhar espaço e reputação a partir do século XIX, não só por conta do estabelecimento do romance como gênero literário maior, mas também em função do crescimento do olhar científico, que buscava privilegiar, no momento da tradução, outros aspectos que não o poético; nesse movimento, nada mais conveniente do que o texto solto, capaz, teoricamente, de manter a "fidelidade" ao conteúdo - como se vê ainda hoje em coleções especializadas de prestígio, como são a "Les Belles Lettres" e a "The Loeb Classical Library".

Aqui cabe fazer um recuo e destacar o trabalho pioneiro e interessantíssimo de Mme. Dacier (Anne Dacier, 1647? 1654?-1720). Filha de um professor de grego e casada com um pupilo do pai, André Dacier, Anne Dacier, além de figura isolada num meio totalmente masculino, foi editora e tradutora de destaque, que se notabilizou, depois de já ter trabalhado com Calímaco, Safo, Anacreonte, Aristófanes, Plauto e Terêncio, pelas traduções em prosa de Homero - a Ilíada, de 1699, e a Odisseia, de 1708 - e por seu envolvimento na segunda fase da chamada "Querela dos 
Antigos e Modernos". Há vários elementos em jogo no projeto tradutório de Mme. Dacier, expostos no prefácio à Ilíada, os quais não me sinto capaz de abordar devidamente, mas neste âmbito vale destacar a ideia central que ela herdara de Pierre Daniel Huet (1630-1721), autor de um De optimo genere interpretandi (1661) — de que no trabalho de transposição poética o conteúdo pode ser superior à forma, e as ideias podem e devem se sobrepor à expressão material da palavra.

É verdade que essa justificativa principal para a opção singularíssima pela prosa — na virada do século XVII para o XVIII — acaba fazendo parte de um paradoxo: como apontou Fabienne Moore num ensaio fundamental, a mesma estudiosa que condenava as narrativas burguesas defendia a forma mais burguesa de se traduzir, justamente pela sua possibilidade de popularização... Mas o interessante é notar que, além dessa vontade "de traduzir para os que não o conhecem", Mme. Dacier estava consciente de que era "certamente melhor verter o que Homero pensou e disse, ainda que de uma forma mais simples e menos poética" (cito aqui a partir da edição de D. Robinson). ${ }^{1}$ Para ela, a limitação da nossa poesia fazia com que poetas antigos como Homero, quando traduzidos em versos, "deixassem de ser poetas"; valia o ditado antigo: seria mais fácil roubar a clava de Hércules... A prosa, ao contrário, era capaz de "seguir as noções do poeta" e "reter a beleza de suas imagens". ${ }^{2} \mathrm{Na}$ opinião da tradutora, Platão já indicara isso, ao pôr em prosa (reformulando o discurso direto em indireto) os versos iniciais da Ilíada (República 3, 386c-387a). Mme. Dacier chega a afirmar que "às vezes há um acabamento, uma beleza, uma energia na prosa que a poesia não pode alcançar" - e para exemplificar ela cita os hebreus e seus livros sagrados, "que fizeram da sua prosa uma espécie de poesia".3

Seria um erro, no entanto, diante dessa rápida exposição, imaginar que a tradução de Anne Dacier é "fiel à letra", dentro do nosso espírito acadêmico, em geral afeito à prosa por tal motivo. Ela mesma deixa claro que não busca uma versão "servil" - e sabemos como o "bom gosto" da época interferiu no resultado do trabalho (seu e de outros), por mais diversas que fossem as orientações; sabemos ainda como o "bom gosto" responde até hoje pela fama geral das traduções para o francês, "de todas as línguas europeias", nos dizeres de Ortega y Gasset (em seu ensaio "Miséria e esplendor da tradução", de 1937), "a que menos facilita a tarefa de traduzir"...

${ }^{1}$ Cf. Robinson (ed.), 2002, p. 187 e 188.

${ }^{2}$ Cf. Robinson (ed.), 2002, p. 188.

${ }^{3}$ Cf. Robinson (ed.), 2002, p. 189.

${ }^{4}$ Cf. Ortega y Gasset, 2013, p. 48 
Essa pequena digressão teve o propósito de mostrar, muito rapidamente, o ganho geral que se pôde ter, como bem anteviu Anne Dacier, com o advento das traduções em prosa da poesia de Homero: em lugar da luta com estilos poéticos que muitas vezes nada tinham a ver com o homérico, e que exigiam graus variados de adaptação do leitor, agora seria possível, por meio de uma forma vernácula mais acessível — afeita à narrativa e, portanto, a um traço fundamental dos poemas homéricos -, entrar em contato de modo mais simples e direto com a poesia (em sentido amplo) de suas ideias e imagens.

É com essa breve introdução em mente que queria comentar inicialmente aqui, já no ambiente da língua portuguesa, duas traduções em prosa da Odisseia, a dos padres Eusébio Dias Palmeira e Manuel Alves Correia, saída originalmente em 1938, em Portugal, e a de Jaime Bruna, ex-professor da Universidade de São Paulo (e tradutor prolífico), saída quase quarenta anos depois, em 1976, aqui no Brasil. Ainda no século XX outras transposições do poema vieram a público, como a de Antônio Pinto de Carvalho (no Brasil) e a de Geminiano Cascais Franco (em Portugal), mas são versões indiretas, feitas a partir do francês, ainda que com muita competência.

Como costuma acontecer com as traduções de viés mais acadêmico, o projeto da "fidelidade" dispensa explicações sobre a atividade realizada e por isso essas duas edições da Odisseia, quais sejam, a de Dias Palmeira/ Alves Correia e a de Jaime Bruna. não trazem nenhum comentário a respeito. Isso significa dizer que o tradutor está empenhado - como Mme. Dacier - em reproduzir tudo o que vai dito no original, sem qualquer constrição formal e rítmica, o que lhe permite, em tese, acomodar com fluência ideias e imagens do grego, sem perda significativa das informações. Um confronto rápido com o original logo desfaz, no entanto, essa ilusão de reprodução ideal do conteúdo. Elegi, para meu comentário, os vinte e dois versos iniciais do famoso Canto XXII da Odisseia, que narra o massacre dos pretendentes, episódio já muito popular entre os antigos. Trata-se de uma passagem curta, mas acredito que representativa das principais tendências exibidas pelos tradutores abordados aqui (por motivo de espaço e clareza, deixarei de fora da discussão minúcias filológicas presentes no trecho, algumas delas com impacto sobre o trabalho do tradutor).

Elaborações sintáticas de modo a deixar Homero mais elegante; omissões de termos repetidos, com o mesmo propósito; acréscimo de alguma ideia ausente no original; e não-tradução de certos termos (por desatenção?): tanto o trabalho de Dias Palmeira/ Alves Correia quanto o de Jaime Bruna mostram exemplos dessas ocorrências. Veja-se, em Dias Palmeira/ Alves Correia, a inclusão do advérbio "imediatamente", logo no primeiro parágrafo; a redução drástica da construção coordenativa, 
com o sumiço da repetição original "flechas/ setas" e da qualificação das mesmas armas como "rápidas". No segundo parágrafo, "morte funesta" traduz, literalmente, "morte má e sorte negra", e ocorrem ainda outras três omissões: "sangue humano/ másculo"; "repeliu-a rapidamente"; e "um grande tumulto pelo palácio":

Dias Palmeira/ Alves Correia (1938):

O prudente Ulisses despojou-se imediatamente dos seus andrajos e, saltando para o grande limiar da porta com o arco e o carcás cheio de frechas, que despejou a seus pés, disse aos pretendentes:

"Já está terminado o certame decisivo. Agora vou atirar a outro alvo, ao qual ainda nenhum homem atirou. Quero ver se lhe acerto e se Apolo me dá essa glória”.

Após estas palavras, dirigiu a frecha amarga contra Antínoo. Ora este ia levar aos lábios uma linda taça de oiro, com duas asas, que tinha já entre as mãos, para beber vinho, sem se preocupar no seu espírito com a morte. Quem, com efeito, poderia pensar que, entre tantos convivas, um só homem, ainda que fosse muito valente, lhe daria morte funesta? Ulisses acertou-lhe com o dardo na garganta, cuja ponta lhe atravessou, de um lado a outro, o macio pescoço. Antínoo tombou para o lado e, ao ser atingido, o copo caiu-lhe das mãos. Um jorro espesso de sangue brotou-lhe logo do nariz; e, dando na mesa com o pé, repeliu-a de si, e os alimentos, o pão e a carne assada espalharam-se pelo chão e sujaram-se no pó.

Os pretendentes, ao verem o homem tombar, fizeram um grande tumulto. ${ }^{5}$

Em Jaime Bruna, os problemas são menos numerosos, ainda que logo de saída ele também evite a repetição original de mesmo verso "flechas/ setas". No parágrafo seguinte, temos "negro destino duma triste morte"; o particípio traduzido por Dias Palmeira/ Alves Correia por "ao ser atingido" desaparece; e o período final é reelaborado, tornando-se mais rebuscado. Sinal do propósito de fundo em comum é perceber como o "e" homérico que vem logo após a fala de Odisseu, "disse", ganha nesses tradutores tratamento quase idêntico: "Após essas palavras"/ "Com essas palavras":

Jaime Bruna (1976):

O solerte Odisseu despojou-se dos andrajos, galgou de um salto a longa soleira, segurando o arco e a aljava cheia; despejou a seus pés as setas ligeiras e disse aos pretendentes:

${ }^{5}$ Cf. Dias Palmeira; Alves Correia, 1994, p. 313. 
"Essa competição inexequível acabou afinal; agora visarei outro alvo, que ainda homem nenhum atingiu, e espero acertar, se Apolo me der essa glória”.

Com essas palavras, endereçou amarga seta a Antínoo, no momento em que ia erguendo uma copa de ouro cinzelada, de duas asas; ele já a segurava nas mãos, para beber vinho, longe de cuidar da morte. Quem, rodeado de comensais, imaginaria que um homem, só entre muitos, por mais valente que fosse, lhe houvera de aprontar o negro destino duma triste morte? No entanto, Odisseu alvejou-o, acertando com a seta na garganta; a ponta varou, sem desvios, o delicado pescoço. Antínoo tombou para um lado; a taça caiu-lhe das mãos; no mesmo instante, subiu-lhe às narinas um jato grosso de sangue humano; com rápido pontapé, arredou de si a mesa, espalhando a comida pelo chão; caíram na sujeira pão e nacos de carne assada.

Ergue-se na mansão um escarcéu dos pretendentes, ao verem o homem caído. ${ }^{6}$

Não se pode negar, contudo, a despeito das "infidelidades", o serviço que essas propostas de tradução prestam no sentido de facilitar o acompanhamento do texto, sobretudo numa passagem narrativa como essa. Note-se, nesse sentido, o desrespeito ao grego e a inclusão de "Antínoo" (que deixa de ser sujeito oculto) no momento em que se fala de sua queda - expediente facilitado pela prosa e capaz de desfazer possíveis ambiguidades. A conclusão é que a suposta fidelidade, nesses projetos, por mais "bíblica" que pretenda ser, trai sempre visões estéticas e tratos com o texto muito particulares e marcados, o que nos joga na dura realidade de um inevitável, e rico, enviesamento.

Vejamos agora, trabalhando ainda com o mesmo trecho da Odisseia, as traduções saídas na primeira década deste século XXI (a mais recente, no entanto, é a de Trajano Vieira, de 2011), que se apresentam como poéticas. Enquanto poesia, é bom deixar claro, ambas poderiam adotar uma feição bastante prosaica, da mesma maneira que traduções em prosa poderiam ter — e às vezes têm — caráter poético. Mas o fato é que, examinadas de perto, elas me parecem prosa com disposição poética (isto é, linha a linha), não havendo nesses textos nada de propriamente poético — no sentido de investirem num projeto de valorização sustentada da forma. É a partir desse sentido específico que estou dando aqui a "poético" — ciente dos inúmeros problemas que essa definição envolve — que julgo possível abordar os

$\overline{{ }^{6} \text { Cf. Bruna, 1996, p. } 256 .}$ 
trabalhos apresentados em verso de Frederico Lourenço e Donaldo Schüler na mesma perspectiva daqueles de Dias Palmeira/ Alves Correia e Jaime Bruna. Se voltarmos às comparações, seria possível dizer que Frederico Lourenço é uma espécie de Richmond Lattimore (o tradutor em versos de Homero mais popular entre os acadêmicos de língua inglesa); e Donaldo Schüler, pela liberdade e o rebaixamento, um Émile Victor Rieu (prosa) combinado com Robert Graves (verso): feitas tanto uma quanto outra por especialistas da área de Letras Clássicas, essas traduções se prenderiam, respectivamente, aos tipos 2 e 3 apresentados no início.

Note-se que, diferentemente das outras vistas aqui, essas trazem textos explicativos sobre o projeto tradutório. No caso do trabalho de Frederico Lourenço, o "Prefácio" da edição portuguesa, de 2003, virou "Nota sobre a tradução" na edição brasileira, de 2011, apenas com a supressão de um breve comentário inicial sobre os trabalhos de Dias Palmeira/ Alves Correia e Cascais Franco, que teriam um "problema de base", "o fato de serem em prosa, o que não só empobrece como dificulta a leitura" (pela dificuldade de se acompanhar a numeração dos versos). Lourenço afirma que a Odisseia foi vertida "com a máxima fidelidade ao original", mas que não se trata de uma tradução "nem arcaizante nem acadêmica". ${ }^{8}$ Ele diz que a "transposição plena do hexâmetro dactílico para o português é impossível, dada a inexistência na nossa língua de sílabas longas e breves", mas que "alguma coisa da paleta sonora do hexâmetro foi possível preservar", e que cultivou "um tipo de verso de extensão moldável, com vincados contornos rítmicos", sendo que no caso de algumas fórmulas procurou "reproduzir, no nível da própria fonética, a musicalidade do original". ${ }^{9}$ Mais à frente, o tradutor afirma que procurou "respeitar também a estética enunciativa do verso homérico no que concerne à alternância entre versos autocontidos, que formam um enunciado completo, e versos que cavalgam no seguinte". Por fim, Lourenço informa que "na maior parte dos casos, foi possível fazer corresponder a cada verso em grego um verso em português", mas que "houve passagens em que tal processo não pareceu exequível”, o que resultou numa Odisseia em português com "alguns versos a mais" - ainda que ressalve que "do conteúdo original, pouco - diria mesmo nada — se perdeu". ${ }^{10}$

${ }^{7}$ Cf. Lourenço, 2003, p. 7.

${ }^{8}$ Cf. Lourenço, 2011, p. 107.

${ }^{9}$ Cf. Lourenço, 2011, p. 108.

${ }^{10}$ Cf. Lourenço, 2011, p. 109. 
Logo de cara, chama atenção a defesa da "máxima fidelidade" e da "perda zero" - típica do tradicional conservadorismo dos filólogos —, numa época em que as reflexões sobre tradução sugerem postura mais cautelosa. Essa ingenuidade, me parece, já desmente por si a afirmação de que não se trata de trabalho acadêmico. Na realidade, esse parece ser, em sua essência, um trabalho norteado pelo espírito da prosa, segundo o qual se deve manter a elegância e a fluência - objetivo que Lourenço alcança com excepcional êxito - em detrimento do ritmo e da forma. Daí soarem como um pouco vazias suas preocupações com a "paleta sonora do hexâmetro", seus "vincados contornos rítmicos" e a "musicalidade do original": a versão tem a marca do ouvido apurado, mas não propriamente poético, porque ao longo do texto não é possível discernir esse tipo de economia formal que ele aponta. $\mathrm{O}$ desrespeito à correspondência absoluta entre o número de versos - que ele admite - , somado à desatenção com os cavalgamentos e o desenho sintático de Homero - que o tradutor não admite —, parece confirmar as suspeitas de que a execução não condiz com a carta de intenções.

$\mathrm{Na}$ passagem sob exame não há, é verdade, versos a mais, mas é perceptível (pelas barras paralelas que inseri no texto, marcando o fim de verso no original) o descuido com o "enjambement". Note-se ainda a troca de "rápidas" por "todas", no terceiro verso, e as omissões de "grande", no segundo verso, de "na garganta", no décimo quinto, de "espesso", no décimo oitavo, e de "pelo palácio", no último. No décimo quarto, "negro destino" vira "escuridão do destino", rompendo o paralelismo, e no nono o sujeito oculto Antino (forma que Lourenço adota para Antínoo) é explicitado, no típico procedimento explicativo da prosa:

Frederico Lourenço (2003):

Em seguida despiu os farrapos o astucioso Ulisses

e deu um salto em direção à soleira, segurando o arco

e a aljava// cheia de setas. Entornou as setas todas

à frente dos pés e assim disse aos pretendentes:

"Na verdade chegou ao fim este certame tremendo.

Agora noutro alvo, que nunca antes foi atingido,// verei se consigo acertar, se Apolo der cumprimento à minha prece".

Assim falou, e contra Antino disparou uma seta amarga.

Ora Antino estava no momento de levar à boca uma bela taça $/ /$ vaso dourado de asa dupla; pegara nela com a mãos, para beber um gole de vinho. O morticínio estava longe dos seus pensamentos. Pois quem dos celebrantes do banquete pensaria// que um homem, isolado entre tantos, ainda que forte, lhe traria a morte malévola e a escuridão do destino? Mas Ulisses disparou contra ele e atingiu-o com a seta, 
cuja ponta lhe atravessou por completo o pescoço macio. Inclinou-se para o lado; a taça caiu-lhe das mãos// ao ser atingido, e logo das narinas jorrou um jato de másculo sangue. Depressa afastou// a mesa com um pontapé e toda a comida foi parar ao chão,// conspurcando o pão e as carnes assadas. Então surgiu entre os pretendentes uma gritaria desmedida, ao verem o homem caído. ${ }^{11}$

A versão de Donaldo Schüler, publicada em três volumes (a única bilíngue), segue caminho diferente, mostrando-se bem mais desnivelada, e pouco criteriosa. No volume 1, ao final de uma breve introdução, lemos um parágrafo em que o tradutor apresenta seu propósito de "afrouxar a carga sintática e vocabular que abafa vozes juvenis", mantendo o "diálogo entre nosso tempo e outros tempos" e tendo "em mira fazer personagens reviverem em nosso dizer coloquial". ${ }^{2}$ Schüler diz ainda que pretendeu "criar ritmos livres, não subordinados a modelos, movimentos próximos à mobilidade do hexâmetro homérico", e reconhece que as fórmulas "aparecem modificadas, moduladas, contornadas em consonância com procedimentos da literatura escrita", recebendo destacado cuidado em relação à sonoridade. ${ }^{13}$ No volume 3 , esse mesmo texto é reapresentado, seguido agora de uma nota "Sobre a tradução". Trata-se de uma reelaboração do eixo central que já havia sido exposto anteriormente — a popularização pelo recurso à coloquialidade. Com base na afirmação de que "tradução fiel não existe", Schüler faz as seguintes afirmações, que destaco:

1) "Quisemos fazer com que Homero deixe de ser um autor para poucos sem deixar de ser Homero".

2) "Optamos por linguagem popular até nas palavras de xingamento. Se correspondem ao original não está em foco. Importa que funcionem em português. A precisão esteve, entretanto, sempre no horizonte de nossas preocupações".

3) "O modernismo brasileiro desvendou insuspeitos recursos poéticos na linguagem coloquial. Recorremos ao sabor de expressões correntes a todo instante, misturamos níveis de linguagem. A sonoridade nos foi preocupação constante. Em lugar de algemar os versos a medidas consagradas, preferimos dar ouvidos aos móveis embalos do hexâmetro. Não se confunda isso com expansão prosaica". ${ }^{14}$

${ }^{11}$ Cf. Lourenço, 2011, p. 493 e 494.

${ }^{12}$ Cf. Schüler, 2007, vol. 1, p. 10.

${ }^{13}$ Cf. Schüler, 2007, vol. 1, p. 10.

${ }^{14}$ Cf. Schüler, 2007, vol. 3, p. 11. 
Assumir o mote modernista é uma opção interessante e, obviamente, válida, mas a proposição geral soa confusa e contraditória. A meu ver, falta, fundamentalmente, justificar a correlação entre a "voz" do texto de partida e a pretendida para o de chegada. É difícil, além do mais, não se ter a impressão de absoluto desprezo pelo ritmo quando Schüler termina versos, como nesta amostragem, com "do", "e o", "me”, "que", "das", "pelo". Se a passagem em foco não traz o registro baixo e de apelo juvenil/popular que é característico desse projeto, e que às vezes é quase o do "poema-piada" (Od. 9, 273-5: “...Que Zeus vá à merda. Nós, os Ciclopes,/ cagamos no poder dele. Um peido na fuça dos/ lá de cima..."), por outro lado não dispensa a paráfrase recriadora - perigosa porque traz consigo a impressão de arbitrária, preguiçosa - e o ritmo sincopado, ágil (sobre essas características, veja-se a resenha de Lilian Sais citada nas referências). O leitor sente, ao final, certo desconforto. Dizer que a tradução fiel não existe é bem diferente de praticar uma recriação própria: uma não leva necessariamente à outra:

Donaldo Schüler (2007):

Odisseu, farto em planos, arranca os farrapos do corpo, salta ao espaçoso limiar com o arco e o carcás carregado de frechas. Esparramados os velozes projéteis a seus pés, a voz valente perpassa o espaço: "Ah! Ah! Acabou o acirrado certame. Mas não me escapa novo escopo, fora da mira de outro frecheiro. Saberei alcançá-lo se Apolo me conceder esta glória”. Antínoo chama-se o alvo da seta certeira. O ouro da taça subia-lhe fulgurante aos lábios. Duplas eram as asas, erguidas por mãos decididas. Rubro rutilava na taça o vinho. A morte não lhe anuviava a mente. Quem pensaria durante folguedos de banquete que um só se lançaria contra muitos, ainda que fosse o melhor, com negros planos de morte e matança? Zuniu a seta. Odisseu visou a garganta. A ponta perfurou a delicada pele do pescoço. Antínoo caiu de costas. A taça saltou das mãos do ferido. Das narinas esguichou um jato de sangue. O pé bateu brusco na perna da mesa. As iguarias rolaram pelo chão. Pão e assados se perderam no pó. O tumulto alvorotou toda a sala. À vista do homem tombado, os convivas// saltaram... ${ }^{15}$

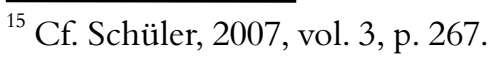


Sim, Frederico Lourenço é poético em certo sentido porque a apresentação do texto em versos já pressupõe uma disposição diferente por parte do leitor (é bom lembrar que traduções norte-americanas ditas "poéticas", como a de Robert Fagles, trazem a marca do prosaísmo tão característico da poesia desse país); a de Donaldo Schüler tem, sim, certo dinamismo poético e a herança haroldiana da ênfase na sonoridade: o conceito de "poético", sabemos, é mutável como um Proteu. No entanto, no sentido em que o estou empregando aqui, faltam a ambas, para que possam receber tal definição, uma economia e um tratamento mais intensivo dado ao original - ou seja, uma preocupação contínua com outros elementos que não apenas a recriação distendida (elegante ou coloquial) do conteúdo - , como se vê nas transposições de Odorico (Ilíada e Odisseia), Nunes (também dos dois épicos) e Haroldo (Ilíada)/ Trajano (Odisseia). Sente-se, nos dois casos, guardadas as enormes diferenças, que se realizou um trabalho de sobrevoo, sem a paciente descida aos detalhes. A poesia homérica, no entanto, tomada em seu valor geral, não se perde - muitas vezes fica até mais acessível, inteligível. São, portanto, traduções fáceis de ler, muito divergentes entre si pelo tom e pelo andamento geral, que se dirigem a públicos distintos. E isso é bom.

\section{Referências}

BRUNA, J. Homero: Odisseia. São Paulo: Cultrix, 1996.

DIAS PALMEIRA, E.; ALVES CORREIA, M. Homero: Odisseia. Lisboa: Sá da Costa, 1994.

LOURENÇO, F. Homero: Odisseia. Lisboa, Cotovia, 2003.

LOURENÇO, F. Homero: Odisseia. São Paulo: Penguin/ Cia. das Letras, 2011.

MOORE, F. Homer revisited: Anne Le Fèvre Dacier's preface to her prose translation of the "Iliad" in early eighteenth-century France. Studies in the literary imagination, Atlanta, vol. 33, n. 2, p. 87-107, 2000.

ORTEGA Y GASSET, J. Miséria e esplendor da tradução (trad. Mauri Furlan e Mara Gonzalez Bezerra). Scientia traductionis, Florianópolis, n. 13, p. 5-50, 2013.

ROBINSON, D. (ed.). Western translation theory. Northampton: St. Jerome Publishing, 2002.

SAIS, L. Resenha da tradução de Donaldo Schüler. Letras Clássicas, São Paulo, vol. 9, p. 253-267, 2005.

SCHÜLER, D. Homero: Odisseia. 3 vols. Porto Alegre: L\&PM, 2007.

STEINER, G. Homer in English. New York: Penguin, 1996. 
